\title{
Inpatient Biophysical Profiles and the Effect on Clinical Decision Making
}

\author{
Diana A. Racusin, MD ${ }^{1}$ Suneet P. Chauhan, MD, DSc ${ }^{1}$ Baha Sibai, MD ${ }^{1}$ Han-Yang Chen, $\mathrm{PhD}^{1}$ \\ Nesochi Adimorah, MD ${ }^{1}$ Mica Piro, BS ${ }^{1}$ Kristen Heye, MD ${ }^{1}$ Charlotte Sharp MSN WHNP-BC ${ }^{1}$ \\ Sean Blackwell, $\mathrm{MD}^{1}$ Jerrie Refuerzo, $\mathrm{MD}^{1}$
}

${ }^{1}$ Department of Obstetrics, Gynecology, and Reproductive Sciences, University of Texas Health Science Center at Houston, McGovern Medical School, Houston, Texas

Am J Perinatol Rep 2020;10:e357-e361.

\author{
Address for correspondence Diana A. Racusin, MD, Department of \\ Obstetrics, Gynecology, and Reproductive Sciences, McGovern \\ Medical School at the University of Texas Health Science Center at \\ Houston, UT Health, 6431 Fannin Street, MSB 3.262, Houston, \\ TX 77030 (e-mail: diana.racusin@uth.tmc.edu).
}

\begin{abstract}
Keywords

- biophysical profile

- antenatal fetal surveillance

- decision making

Objective Our primary objective was to determine whether biophysical profiles (BPP) performed on the antepartum unit result in changes in clinical decision making. Study Design A retrospective cohort chart review was performed among women who had a BPP during hospital admission. BPP status was categorized as normal (8/8 points) and abnormal ( $6 / 8$ or less points). The primary outcome, clinical decision making, was the need for prolonged external fetal monitoring (defined as $>2$ hours) or decision to proceed with delivery. Secondary outcomes included mode of delivery, indicated preterm delivery, birth weight, 5-minute Apgar's score $<7$, and neonatal intensive care unit (NICU) admission.

Results Among our cohort $(n=186), 85.5 \%(n=159)$ had a normal BPP. Delivery management was altered in one case $(0.54 \%)$ by the BPP findings, and there were no BPPs that resulted in need for prolonged monitoring. Compared with women with normal BPP, women with abnormal BPPs were more likely to deliver at $<37$ weeks, to be admitted to the NICU, or have a 5-minute Apgar's score $<7$.

Conclusion In-hospital BPPs alter clinical decision making in less than $1 \%$ of cases.
\end{abstract}

The goal of antenatal fetal surveillance is to identify fetal compromise that could lead to fetal demise. Reactive non stress tests (NSTs) and reassuring biophysical profiles (BPPs) are based on the premise that fetal hypoxia will result in measurable fetal physiologic alterations. ${ }^{1-9}$

The present paradigm of antenatal surveillance is the result of a screening methodology evolution based in chronologically available technology and not due to rigorous comparison of modalities. ${ }^{10}$ Nevertheless, assessment of fetal wellbeing by examining fetal biophysical variables has become a commonly used tool in conventional outpatient prenatal care. ${ }^{5,11-13}$

The utility of BPPs, however, is not well studied in hospitalized patients. Current recommendations clearly advise against the use of BPPs in lieu of standard intrapartum monitoring. ${ }^{14}$ In our inpatient antenatal testing protocol,

received

January 22, 2020

accepted

March 15, 2020
DOI https://doi.org/

10.1055/s-0040-1717141. ISSN 2157-6998. pregnant women routinely undergo twice daily NSTs as a mean of antenatal fetal surveillance. While antenatal fetal surveillance paradigms vary by institution, it is unclear whether the addition of BPPs to twice daily NSTs alters clinical decision making or maternal or fetal outcomes. In fact, several these patients have known pregnancy complications, such as preterm premature rupture of membranes preterm premature rupture of membranes (PPROM), which may alter the results of the BPP.

The primary objective of this study was to determine whether BPPs performed in the hospital on the antepartum unit result in change of the primary outcome, clinical decision making. The secondary objective was to examine several secondary clinical outcomes between the BPP groups (normal vs. abnormal).
Copyright $\odot 2020$ by Thieme Medical Publishers, Inc., 333 Seventh Avenue, New York, NY 10001, USA. Tel: +1(212) 760-0888.
License terms

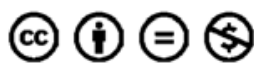




\section{Materials and Methods}

We conducted a retrospective cohort study by reviewing medical charts. Charts were queried for every woman admitted to the antepartum service at Memorial Hermann Hospital (Houston, TX) between August 2016 and April 2017. Per hospital policy, all antepartum patients are monitored twice daily with NSTs lasting for 1 hour at a time. The decision to perform a BPP is made by the managing physician and is frequently made independently of the results of NST. This study included those who were screened with BPP in addition to routine, twice daily NSTs. BPPs were performed by sonographers and interpreted by maternal fetal medicine physicians. The finalized BPP report is scanned into the patient's medical record. Patients with multiple gestations were excluded. In patients who had multiple BPPs, the last BPP was used for statistical analysis, as it would be the BPP most likely to result in changes in clinical management. This retrospective study was conducted with full permission from the Institutional Review Board (HSC-MS-17-0547) through the Division of Maternal Fetal Medicine at McGovern Medical School-UT Health.

Multiple data points were collected including maternal demographics, pregnancy outcomes, neonatal outcomes, and indications for hospitalization and delivery. Indications for hospital admission were categorized in the following groupings: PPROM, glucose optimization in the setting of diabetes, blood pressure optimization or preeclampsia, preterm labor or contractions, vaginal bleeding or placental abnormality, fetal heart rate tracing abnormality, fetal growth restriction, and other. Delivery indications include labor, elective delivery, abnormal placentation, fetal heart rate abnormalities, hypertensive disorder, diabetes (gestational or pregestational), ruptured membranes, oligohydramnios, fetal growth restriction, and other.

The main explanatory variable was BPP status, categorized into two groups: normal $\mathrm{BPP}=8 / 8$ points versus abnormal BPP $\leq 6 / 8$ points. The retrospective nature of this study precluded use of the 10-point BPP for analysis. Documentation of the timing and relationship of NST to BPP was inconsistent and limited. Many times, the BPPs are performed either before the first NST of the day or hours after. The NSTs are not necessarily interpreted or reported to the physician interpreting the BPP. For this reason, it is our practice to report our BPPs on an 8point scale. The primary outcome, clinical decision making, was defined as the need for prolonged fetal monitoring (NST $>2$ hours) or decision to proceed with delivery. The secondary outcomes included mode of delivery, preterm delivery (defined as gestational age at delivery $<37$ weeks), birth weight (normalized to gestational age), ${ }^{15} 5$-minute Apgar's score $<7$, and neonatal intensive care unit (NICU) admission. If a woman had multiple BPPs during her hospital admission, the last BPP was used for inclusion in the study.

Descriptive statistics were used to summarize data for participants according to their BPP groups. Data were presented as mean (standard deviation [SD]) or frequency (\%). Differences in the maternal characteristics, indications for admission, and clinical outcomes stratified by BPP groups were examined using the $t$-test for continuous variables, and Chi-square test or
Fisher's exact test, as appropriate, for categorical variables. A $p$-value of $<0.05$ was considered statistically significant. All statistical analyses were conducted using SAS 9.4.

\section{Results}

All antepartum patients who had a BPP during the study period were enrolled $(n=186)$. A total of 268 BPPs were reviewed as some participants had multiple BPPs. - Table 1 delineates participants' characteristics. In our study population, $85.5 \%(n=159)$ had normal BPP (8/8 points) and $14.5 \%$ $(n=27)$ had abnormal BPP (6/8 or less points); the majority were African American (41.6\%), multiparous (66.7\%), and overweight or obese (84.5\%). Compared with women with normal BPP, those with abnormal BPP were more likely to receive corticosteroids for fetal lung maturity prior to delivery, and have lower average gestational age at time of BPP but less likely to be overweight or obese.

When examining the primary outcome, out of 186 patients reviewed, only 1 BPP study (0.54\%) altered clinical decision making, defined as the need to prolong external fetal heart rate monitoring or decision to proceed with delivery. The patient in question was delivered because of an incidental discovery of oligohydramnios on her BPP. No BPPs resulted in prolonged fetal monitoring. If prolonged fetal monitoring was performed $(n=26)$ it was secondary to another clinical indication such as category-II fetal heart rate tracing or uterine contractions.

-Table 2 presents indications for hospital admission and delivery. Our results showed that indications for hospital admission varied between BPP groups. PPROMs (66.7\%) followed by hypertensive disorders (14.8\%) are the leading causes of hospital admission amongst abnormal BPPs. Among normal BPPs, leading reasons for hospitalization included fetal growth restriction (33.3\%), hypertensive disorders (25.6\%), and preterm labor/contractions (16.0\%). Similarly, indications for delivery also differed between BPP groups. The leading cause for delivery among normal BPPs were hypertensive disorders (21.9\%) followed by labor (16.8\%); however, in abnormal BPP group, $40.7 \%$ were delivered due to labor and $11.1 \%$ for preeclampsia and other hypertensive disorders.

- Table 3 presents the secondary outcomes. Compared with women with normal BPP (8/8 points), women with abnormal BPP (6/8 or less points) were more likely to deliver at preterm ( 55.0 vs. $100.0 \%, p<0.001$ ), be admitted to the NICU ( 51.0 vs. $92.6 \%, p<0.001)$, or have a low 5-minute Apgar's score $(<7$; 4.1 vs. $18.5 \%, p=0.004)$. There was no significant difference in the mode of delivery between BPP groups ( $p=0.911)$ or birth weight normalized to gestational age at birth $(p=0.062)$. Notably, while stillbirths occurred in both groups $(n=3)$, there was no significant difference found between groups.

\section{Discussion}

Our study found that inpatient BPPs rarely affected clinical decision making. Of the 186 patients reviewed (with a total of 268 BPPs performed), only 1 BPP study altered our primary outcome. This data suggest that physicians are infrequently 
Table 1 Maternal characteristics

\begin{tabular}{|c|c|c|c|c|c|c|c|}
\hline & \multirow[t]{2}{*}{ All } & \multirow[t]{3}{*}{$\%$} & Normal & \multirow[t]{3}{*}{$\%$} & Abnormal & \multirow[t]{3}{*}{$\%$} & \multirow[t]{3}{*}{$p$} \\
\hline & & & BPP $8 / 8$ & & $\mathrm{BPP} \leq 6 / 8$ & & \\
\hline Variable & $n=186$ & & $n=159$ & & $n=27$ & & \\
\hline Age (y), (mean/SD) & 29.1 & 6.1 & 29.3 & 6.0 & 28.0 & 6.9 & 0.292 \\
\hline \multicolumn{8}{|l|}{ Race and ethnicity } \\
\hline White & 32 & 17.3 & 27 & 17 & 5 & 19.2 & \multirow[t]{5}{*}{0.394} \\
\hline African American & 77 & 41.6 & 70 & 44 & 7 & 26.9 & \\
\hline Hispanic & 50 & 27 & 40 & 25.2 & 10 & 38.5 & \\
\hline Asian & 4 & 2.2 & 4 & 2.5 & 0 & 0 & \\
\hline Other & 22 & 11.9 & 18 & 11.3 & 4 & 15.4 & \\
\hline \multicolumn{8}{|l|}{ Overweight or obese $\left(\mathrm{BMI} \geq 30 \mathrm{~kg} / \mathrm{m}^{2}\right.$ ) } \\
\hline No & 28 & 15.5 & 20 & 12.8 & 8 & 32.0 & \multirow[t]{2}{*}{0.014} \\
\hline Yes & 153 & 84.5 & 136 & 87.2 & 17 & 68.0 & \\
\hline Gestational age at BPP (wk), (mean/SD) & 32.8 & 3.0 & 33.0 & 3.0 & 31.1 & 2.8 & 0.002 \\
\hline \multicolumn{8}{|l|}{ Multiparous } \\
\hline No & 62 & 33.3 & 51 & 32.1 & 11 & 40.7 & \multirow[t]{2}{*}{0.377} \\
\hline Yes & 124 & 66.7 & 108 & 67.9 & 16 & 59.3 & \\
\hline \multicolumn{8}{|l|}{ Antenatal steroids } \\
\hline No & 59 & 32.2 & 57 & 36.5 & 2 & 7.4 & \multirow[t]{2}{*}{0.002} \\
\hline Yes & 124 & 67.8 & 99 & 63.5 & 25 & 92.6 & \\
\hline \multicolumn{8}{|l|}{ Pregestational diabetes } \\
\hline No & 169 & 91.4 & 142 & 89.9 & 27 & 100 & \multirow[t]{2}{*}{0.134} \\
\hline Yes & 16 & 8.6 & 16 & 10.1 & 0 & 0 & \\
\hline \multicolumn{8}{|l|}{ Gestational diabetes } \\
\hline No & 172 & 93 & 147 & 93 & 25 & 92.6 & \multirow[t]{2}{*}{1.000} \\
\hline Yes & 13 & 7 & 11 & 7 & 2 & 7.4 & \\
\hline \multicolumn{8}{|l|}{ Chronic hypertension } \\
\hline No & 151 & 82.1 & 126 & 80.3 & 25 & 92.6 & \multirow[t]{2}{*}{0.175} \\
\hline Yes & 33 & 17.9 & 31 & 19.7 & 2 & 7.4 & \\
\hline \multicolumn{8}{|l|}{ Gestational hypertension or preeclampsia } \\
\hline No & 130 & 70.7 & 109 & 69.4 & 21 & 77.8 & \multirow[t]{2}{*}{0.379} \\
\hline Yes & 54 & 29.3 & 48 & 30.6 & 6 & 22.2 & \\
\hline
\end{tabular}

Abbreviation: BMI, body mass index; BPP, biophysical profile; SD, standard deviation.

Note: data are presented as $n(\%)$.

Demographics of study cohort. Participants with abnormal BPPs were more likely to deliver at earlier gestational ages, receive corticosteroids, and were less likely to be overweight or obese.

relying on BPP data to manage hospitalized patients. Additionally, our data reflects that BPPs are frequently being ordered when there is a high pretest probability of an abnormal result. For example, decreased amniotic fluid is expected in the setting of PPROMs. This may give a BPP score of $\leq 6 / 8$ but likely would not change the physician's decision making or patient's clinical outcome.

Our findings are notable, especially in the current health care climate where cost is a significant concern. BPPs are considerably more costly that nonstress tests. In a trial of 135 patients with PPROMs randomized to daily BPPs vs daily nonstress tests, Lewis et al demonstrated that the total daily cost of biophysical profile was $\$ 78,000$ greater in the BBP group as compared with the NST group. This cost is significantly higher today as the study was published in 1999 Lewis et al. ${ }^{16}$

This study has multiple strengths. This data are representative of clinical practice in a large academic referral center encompassing both academic and private practice physicians and, therefore, a variety of practice patterns were observed. This data encompass the common indications for hospitalization and delivery and, therefore, comprehensively address the majority of clinical scenarios in which BPPs are utilized. Importantly, this study is practical and applicable to daily clinical practice, addressing issues faced daily by physicians. 
Table 2 Indications for hospital admission and delivery

\begin{tabular}{|c|c|c|c|c|c|c|c|}
\hline & \multirow[t]{2}{*}{ All } & \multirow[t]{3}{*}{$\%$} & Normal & \multirow[t]{3}{*}{$\%$} & Abnormal & \multirow[t]{3}{*}{$\%$} & \multirow[t]{3}{*}{$p$} \\
\hline & & & \multirow{2}{*}{$\begin{array}{l}\text { BPP }(8 / 8) \\
n=159\end{array}$} & & \multirow{2}{*}{$\begin{array}{l}\mathrm{BPP}(\leq 6 / 8) \\
n=27\end{array}$} & & \\
\hline Variable & $n=186$ & & & & & & \\
\hline \multicolumn{8}{|l|}{ Indication for hospitalization } \\
\hline Unknown/undocumented & 4 & 2.2 & 4 & 2.6 & 0 & 0.0 & \multirow[t]{10}{*}{$<0.001$} \\
\hline PPROM & 19 & 10.4 & 1 & 0.6 & 18 & 66.7 & \\
\hline Glucose optimization (DM) & 4 & 2.2 & 4 & 2.6 & 0 & 0.0 & \\
\hline Blood pressure optimization/preeclampsia & 44 & 24.0 & 40 & 25.6 & 4 & 14.8 & \\
\hline Preterm labor/contractions & 26 & 14.2 & 25 & 16.0 & 1 & 3.7 & \\
\hline Term labor/term rupture of contractions & 16 & 8.7 & 16 & 10.3 & 0 & 0.0 & \\
\hline Vaginal bleeding & 6 & 3.3 & 5 & 3.2 & 1 & 3.7 & \\
\hline Fetal heart rate abnormalities & 9 & 4.9 & 9 & 5.8 & 0 & 0.0 & \\
\hline Fetal growth restriction & 55 & 30.1 & 52 & 33.3 & 3 & 11.1 & \\
\hline \multicolumn{7}{|l|}{ Other } & \\
\hline \multicolumn{8}{|l|}{ Indication to deliver } \\
\hline Unknown/undocumented & 25 & 13.7 & 23 & 14.8 & 2 & 7.4 & \multirow[t]{11}{*}{0.020} \\
\hline Labor (preterm or term) & 37 & 20.3 & 26 & 16.8 & 11 & 40.7 & \\
\hline $\begin{array}{l}\text { Elective induction of labor/ } \\
\text { scheduled cesarean delivery at term }\end{array}$ & 25 & 13.7 & 24 & 15.5 & 1 & 3.7 & \\
\hline $\begin{array}{l}\text { Abnormal placentation (placenta accreta, } \\
\text { placenta previa) }\end{array}$ & 5 & 2.7 & 4 & 2.6 & 1 & 3.7 & \\
\hline Fetal heart rate abnormalities & 14 & 7.7 & 13 & 8.4 & 1 & 3.7 & \\
\hline $\begin{array}{l}\text { Preeclampsia, gestational hypertension, } \\
\text { chronic hypertension }\end{array}$ & 37 & 20.3 & 34 & 21.9 & 3 & 11.1 & \\
\hline Diabetes (pregestational or gestational) & 6 & 3.3 & 6 & 3.9 & 0 & 0.0 & \\
\hline Ruptured membranes & 4 & 2.2 & 2 & 1.3 & 2 & 7.4 & \\
\hline Oligohydramnios & 9 & 4.9 & 8 & 5.2 & 1 & 3.7 & \\
\hline Fetal growth restrictions & 13 & 7.1 & 11 & 7.1 & 2 & 7.4 & \\
\hline Other & 7 & 3.8 & 4 & 2.6 & 3 & 11.1 & \\
\hline
\end{tabular}

Abbreviations: BPP, biophysical profile; DM, diabetes; PPROM, preterm premature rupture of the membranes.

Note: vaginal bleeding: placenta previa, placenta accreta, placental abruption, etc.

Ruptured membranes: PPROM or ruptured membranes at term with no labor.

Indications for hospital admission and delivery. Indications for hospital admission and delivery were diverse and differed among participants with normal BPPs as compared with those with abnormal BPPs.

\section{Limitations}

Our study is not without limitations. The retrospective nature of our study is limiting, as is the relatively small sample size. These limitations made it difficult to accurately comment on full 10-point BPPs. We were not able to assess the total number of antepartum admissions during this time period and, therefore, are unable to comment on the percentage of antepartum patients who received a BPP in addition to routine twice daily NSTs. Furthermore, we were unable to comment on whether normal BPPs allowed for prolongation of pregnancy when patients may have otherwise been delivered. A prospective study would allow better characterization and interpretation of fetal heart rate tracings and assessment of clinical thought processes. Final- ly, this study does not have sufficient power to address the impact of antenatal testing on the detection or prediction of intrauterine fetal demise. While there was not a statistical difference in stillbirths between groups, its relationship with BPP would best be explored in a large, prospective trial.

\section{Conclusion}

In conclusion, BPP did not increase rates of delivery or prolonged fetal monitoring when compared with standard nonstress tests in a diverse, inpatient population. Given lack of proven benefit and known increase in cost related to BPPs among hospitalized women, the optimal methodology for inpatient antenatal fetal surveillance deserves further prospective investigation. 
Table 3 Clinical outcomes

\begin{tabular}{|c|c|c|c|c|c|c|c|}
\hline & & & Normal & & Abnormal & & \\
\hline & All & & BPP $(8 / 8)$ & & $\mathrm{BPP}(\leq 6 / 8)$ & & \\
\hline Outcomes & $n$ & $\%$ & $n$ & $\%$ & $n$ & $\%$ & $p$ \\
\hline $\begin{array}{l}\text { Mode of delivery: } \\
\text { cesarean }\end{array}$ & $93 / 176$ & $52.8(45.4-60.2)$ & $79 / 149$ & $53.0(44.9-60.9)$ & $14 / 27$ & $51.9(33.5-69.7)$ & 0.911 \\
\hline $\begin{array}{l}\text { Preterm delivery } \\
(<37 \text { weeks })\end{array}$ & $108 / 175$ & $61.7(54.3-68.7)$ & $82 / 149$ & $55.0(47.0-62.9)$ & $26 / 26$ & 100.0 & $<0.001$ \\
\hline \multicolumn{8}{|l|}{ Birth weight } \\
\hline SGA & $3 / 176$ & $1.7(0.5-5.2)$ & $3 / 149$ & $2.0(0.6-6.1)$ & $0 / 27$ & 0.0 & \multirow[t]{3}{*}{0.062} \\
\hline LGA & $73 / 176$ & $41.5(34.4-48.9)$ & $67 / 149$ & $45.0(37.1-53.2)$ & $6 / 27$ & $22.2(10.3-41.6)$ & \\
\hline AGA & $100 / 176$ & $56.8(49.4-64.0)$ & $79 / 149$ & $53.0(44.9-60.9)$ & $21 / 27$ & $77.8(58.4-89.7)$ & \\
\hline $\begin{array}{l}\text { 5-minute Apgar's } \\
\text { score }<7\end{array}$ & $11 / 175$ & $6.3(3.5-11.0)$ & $6 / 148$ & $4.1(1.8-8.8)$ & $5 / 27$ & $18.5(7.9-37.7)$ & 0.004 \\
\hline NICU admission & $101 / 176$ & $57.4(49.9-64.5)$ & $76 / 149$ & $51.0(43.0-59.0)$ & $25 / 27$ & $92.6(74.6-98.2)$ & $<0.001$ \\
\hline Stillbirth & $3 / 176$ & $1.7(0.5-5.2)$ & $1 / 149$ & $0.7(0.1-4.7)$ & $2 / 27$ & $7.4(1.8-25.4)$ & 0.062 \\
\hline
\end{tabular}

Abbreviations: AGA, appropriate for gestational age; BPP, biophysical profile; LGA, large for gestational age; NICU, neonatal intensive care unit; SGA, small for gestational age.

Note: maternal and neonatal outcomes. Maternal and neonatal outcomes differed between participants with normal and abnormal BPPs.

\section{Author Contributions}

D.A.R. wrote the manuscript. D.A.R. and N.A. extracted and analyzed the data. K.H. and C.S. assisted with data input. H. Y.C. performed statistical analyses. S.P.C., S.B., B.S., and J.R. guided experimental design and researched data. All coauthors reviewed/edited the manuscript and contributed to the discussion.

\section{Presented at a Meeting}

Poster session (poster no.: 23 B) presented at 2018 ACOG Annual Clinical \& Scientific Meeting, April 27-30, 2018, Austin, TX.

Funding

None.

\section{Conflict of Interest}

The authors report no conflict of interest.

\section{References}

1 Yoon BH, Romero R, Roh CR, et al. Relationship between the fetal biophysical profile score, umbilical artery Doppler velocimetry, and fetal blood acid-base status determined by cordocentesis. Am J Obstet Gynecol 1993;169(06):1586-1594

2 Boekkooi PF, Baan J Jr., Teitel D, Rudolph AM. Chemoreceptor responsiveness in fetal sheep. Am J Physiol 1992;263(1, Pt 2):H162-H167

3 Koos BJ, Sameshima H, Power GG. Fetal breathing, sleep state, and cardiovascular responses to graded hypoxia in sheep. J Appl Physiol (1985) 1987;62(03):1033-1039

4 Manning FA, Platt LD, Sipos L. Antepartum fetal evaluation: development of a fetal biophysical profile. Am J Obstet Gynecol 1980;136(06):787-795

5 Manning FA, Baskett TF, Morrison I, Lange I. Fetal biophysical profile scoring: a prospective study in 1,184 high-risk patients. Am J Obstet Gynecol 1981;140(03):289-294
6 Natale R, Clewlow F, Dawes GS. Measurement of fetal forelimb movements in the lamb in utero. Am J Obstet Gynecol 1981;140 (05):545-551

7 Manning FA, Harman CR, Morrison I, Menticoglou S. Fetal assessment based on fetal biophysical profile scoring. IV. An analysis of perinatal morbidity and mortality. Am J Obstet Gynecol 1990;162 (02):398-402

8 Manning FA, Harman CR, Morrison I, Menticoglou SM, Lange IR, Johnson JM. Fetal assessment based on fetal biophysical profile scoring. IV. An analysis of perinatal morbidity and mortality. Am J Obstet Gynecol 1990;162(03):703-709

9 Manning FA, Snijders R, Harman CR, Nicolaides K, Menticoglou S, Morrison I. Fetal biophysical profile score. VI. Correlation with antepartum umbilical venous fetal pH. Am J Obstet Gynecol 1993; 169(04):755-763

10 Manning FA. Antepartum fetal testing: a critical appraisal. Curr Opin Obstet Gynecol 2009;21(04):348-352

11 Clark SL, Sabey P, Jolley K. Nonstress testing with acoustic stimulation and amniotic fluid volume assessment: 5973 tests without unexpected fetal death. Am J Obstet Gynecol 1989;160 (03):694-697

12 Miller DA, Rabello YA, Paul RH. The modified biophysical profile: antepartum testing in the 1990s. Am J Obstet Gynecol 1996;174 (03):812-817

13 Nageotte MP, Towers CV, Asrat T, Freeman RK. Perinatal outcome with the modified biophysical profile. Am J Obstet Gynecol 1994; 170(06):1672-1676

14 American College of Obstetricians and Gynecologists. Committee on practice bulletins. Antepartum fetal surveillance. ACOG practice bulletin no. 145. Obstet Gynecol 2014;124(01):182-192

15 Duryea EL, Hawkins JS, McIntire DD, Casey BM, Leveno KJ. A revised birth weight reference for the United States. Obstet Gynecol 2014;124(01):16-22

16 Lewis DF, Adair CD, Weeks JW, Barrilleaux PS, Edwards MS, Garite TJ. A randomized clinical trial of daily nonstress testing versus biophysical profile in the management of preterm premature rupture of membranes. Am J Obstet Gynecol 1999;181(06): 1495-1499 